\title{
The consumption of exergy for lignite drying with different technologies: a comparative theoretical study
}

\author{
Liu, M. ${ }^{a}$; Wang, S. ${ }^{\text {a }}$ Liu, R. ${ }^{\text {a }}$; Han, X. ${ }^{\text {a }}$ Yan, J. ${ }^{a^{*}}$ \\ a State Key Laboratory of Multiphase Flow in Power Engineering. Xi'an Jiaotong University, Xi'an, \\ 710049, P. R. of China
}

*E-mail of the corresponding author: yanji@mail.xjtu.edu.cn

\begin{abstract}
Pre-drying is an effective method to upgrade lignite and broaden its utilization areas. Various drying technologies could be applied to pre-dry lignite. The drying temperature in these drying technologies are different, which means that energy at different grades is used in these dryers. To analyze the irreversibilities of drying process, the exergetic analysis models are developed in this study. The exergy feeding and consumption rates are defined as the indicators. Various lignite drying technologies are calculated and quantitatively compared. Results show that exergy consumption rate for steam fluid-bed dryer is the smallest, which is $432.6 \mathrm{~kJ}\left(\mathrm{~kg} \mathrm{H}_{2} \mathrm{O}\right)^{-1}$.
\end{abstract}

Keywords: lignite; drying technologies; exergy analysis; thermodynamics 


\section{Introduction}

Lignite, a kind of low rank coal, is widely used as feeding fuel for power plants. However, power plants directly using raw lignite always have low efficiency and high pollutant emissions. Pre-drying is a proved method to improve the utilization efficiency of lignite ${ }^{[1]}$. Many types of dryers could be applied to dry lignite. The heat consumption rate is usually used to evaluate the performance of dryers, which is defined as the amount of energy consumed to evaporate $1 \mathrm{~kg}$ water with the unit of $\mathrm{kJ}\left(\mathrm{kg} \mathrm{H}_{2} \mathrm{O}\right)^{-1}$. However, energies used to dry lignite are in different grades. The heat consumption rate could not perfectly reflect performances of dryers based on the second law of thermodynamics. Exergy is a concept of thermodynamics expressing the maximum useful work possible contained in energy ${ }^{[2]}$. It is widely used to evaluate energy grades and the performance of energy processes.

Exergetic analyses were conducted on various lignite dryers in this study. Lignite drying technologies were reviewed firstly and thermodynamic analysis models were then developed. The exergy feeding and consumption rates are defined to evaluate the performance of dryers in the viewpoint of exergetic analysis and are compared quantitatively for various lignite dryers.

\section{Materials and Methods}

\subsection{Lignite drying technologies}

Drying of lignite could be classified to evaporative drying and mechanical-thermal dewatering. In this paper, we focus on the evaporative drying technologies. The evaporative drying is an energy intensive process, because water in lignite needs to absorb a lot of heat to evaporate. For the evaporative drying technologies, flue-gas or steam could be applied as the drying heat sources. Dryers uses steam as heating source are classified as steam dryers, including rotary-tube dryer and steam fluid-bed dryer. Characteristics and working parameters of steam dryers are listed in Table 1. When flue-gas is used to pre-dry lignite, the dryers are classified as flue-gas dryers. Characteristics and working conditions of fluegas dryers are listed in Table 2.

Table 1 Operation parameters of steam dryers ${ }^{[3]}$

\begin{tabular}{lccc}
\hline \multirow{2}{*}{ Dryer type } & Characteristics & \multicolumn{2}{c}{ Heating medium parameters } \\
& Inlet & Outlet \\
\hline $\begin{array}{l}\text { Rotary- } \\
\text { tube dryers }\end{array}$ & $\begin{array}{c}\text { Using air as carrier as evaporative } \\
\text { moisture; consisted of a drum equipped } \\
\text { with tubes. }\end{array}$ & $\sim 180^{\circ} \mathrm{C} / 0.4 \sim 0.5 \mathrm{MPa}$ & $\sim$ Saturated \\
$\begin{array}{l}\text { Steam } \\
\text { fluid-bed } \\
\text { dryers }\end{array}$ & $\begin{array}{c}\text { Lignite drying in slightly superheated } \\
\text { steam; steam fluid-bed with internal } \\
\text { heaters. }\end{array}$ & $\sim 140^{\circ} \mathrm{C} / 0.32 \mathrm{MPa}$ & $\sim$ Saturated \\
& & & water \\
\hline
\end{tabular}




\begin{tabular}{|c|c|c|c|}
\hline \multirow{2}{*}{ Dryer type } & \multirow{2}{*}{ Characteristics } & \multicolumn{2}{|c|}{$\begin{array}{l}\text { Heating medium } \\
\text { temperature } /{ }^{\circ} \mathrm{C}\end{array}$} \\
\hline & & Inlet & Outlet \\
\hline Rotary & Drying along with disintegration; cocurrent mode. & 750 & 120 \\
\hline Pneumatic & $\begin{array}{c}\text { Short drying time; Lignite lifted by drying gas } \\
\text { during pneumatic transport drying. }\end{array}$ & 600 & 100 \\
\hline Fluid-bed & $\begin{array}{l}\text { Easy to control; High drying intensity due to good } \\
\text { mixing and high temperature heating medium. }\end{array}$ & 450 & 75 \\
\hline moving bed & $\begin{array}{l}\text { Possibility of full automation; compact } \\
\text { construction and simple design. }\end{array}$ & 175 & 80 \\
\hline
\end{tabular}

\subsection{Thermodynamic analysis models}

\subsubsection{Dryer model}

The dryer model is indicated in Fig.1. As shown in Fig.1, $1 \mathrm{~kg}$ raw lignite is fed into the dryer, and $\lambda \mathrm{kg}$ water contained in lignite is dried out. $m_{\mathrm{a}} \mathrm{kg}$ air is leaked into or used as carrier gas for drying $1 \mathrm{~kg}$ raw lignite. $m_{\mathrm{h}} \mathrm{kg}$ heating medium (flue-gas or steam) releases heat in the dryer to dry lignite. In some types of dryers the heating medium directly contacts with lignite and leaves the dryer as dryer exhaust. While in some indirect dryers (rotarytube dryer, etc.), the heating medium only exchanges heat in the dryer.

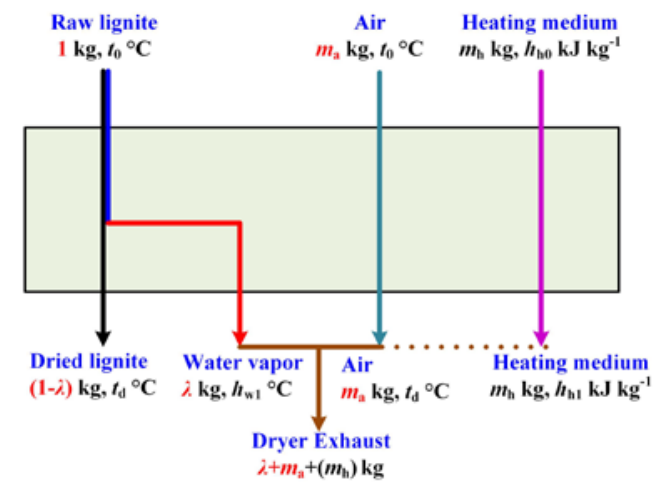

Fig. 1 Schematic diagram of Dryer.

The degree of pre-drying, $\lambda$, is defined to express the mass of water removed from per unit mass of raw lignite as

$$
\lambda=\frac{M_{\text {raw }}-M_{u p g}}{1-M_{u p g}}
$$


where $M_{\text {raw }}$ and $M_{\text {upg }}$ are the mass of water contained in per unit mass of raw and dried lignite, respectively.

The minimum energy consumption, which is only absorbed by lignite to increase temperature and water to evaporate, for drying $1 \mathrm{~kg}$ lignite could be evaluated with

$$
q_{d 0}=\lambda \cdot\left(h_{d w}-h_{w 0}\right)+(1-\lambda) \cdot\left(h_{c 1}-h_{c 0}\right)
$$

where $h_{d w}$ and $h_{w 0}$ are enthalpies of the water contained in dryer exhaust and raw lignite respectively, $\mathrm{kJ} \mathrm{kg}^{-1} ; h_{c 1}$ and $h_{c 0}$ are enthalpies of dried lignite at the outlet and inlet temperatures respectively, $\mathrm{kJ} \mathrm{kg}^{-1}$.

The energy absorbed by possible in-leaking or carrier air is

$$
q_{d a}=m_{a} \cdot C p_{a}\left(t_{d}-t_{0}\right)
$$

where $C p_{a}$ is the specific heat capacity of air, $\mathrm{kJ} \mathrm{kg}^{-1} \mathrm{~K}^{-1} ; t_{d 1}$ and $t_{a 0}$ are temperatures of dryer exhaust and ambient respectively, ${ }^{\circ} \mathrm{C}$.

Based on the energy balance in the dryer, the mass of heating medium is

$$
m_{h}=\frac{q_{d 0}+q_{d a}}{\eta_{d} \cdot\left(h_{h 0}-h_{h 1}\right)}
$$

where $h_{h 0}$ and $h_{h 1}$ are enthalpies of heat medium led into and output from the dryer, kJ $\mathrm{kg}^{-1} ; \eta_{d}$ is the thermal efficiency of dryer, $\mathrm{kJ} \mathrm{kg}^{-1}$.

To evaluate the mass flow rate of drying heat source, the rate of drying medium to dry out 1 $\mathrm{kg}$ water is defined as

$$
K_{h}=\frac{m_{h}}{\lambda}
$$

\subsubsection{Exergetic analysis model}

The dead point is the benchmark for the exergetic analysis. When the exergy carried by the dryer exhaust is recovered by cooling, the dryer exhaust could be cooled to the ambient temperature and becomes saturated moist gas. Therefore, the compositions of saturated moist gas is defined as the deadpoint compositions. The deadpoint pressure and temperature for the exergetic analysis are

$$
p_{0}=0.1 \mathrm{MPa}
$$


In the drying process, substances include lignite, gas (flue-gas and air), water (liquid and steam) and dryer exhaust. Assumptions of ideal gas mixture for the dryer exhaust are used. The exergy of water component is calculated with

$$
E_{w}=h_{w}-h_{w 0}-T_{0}\left(s_{w}-s_{w 0}\right)+\bar{R}_{w} T_{0} \ln \frac{y_{w}}{y_{w 0}}
$$

where $h_{\mathrm{w}}$ and $h_{\mathrm{w} 0}$ are the enthalpies of water at calculation and deadpoint conditions respectively, $\mathrm{kJ} \mathrm{kg}^{-1} ; s_{\mathrm{w}}$ and $s_{\mathrm{w} 0}$ and are the entropies at calculation and deadpoint conditions respectively, $\mathrm{kJ} \mathrm{kg}^{-1} \mathrm{~K}^{-1} ; \bar{R}_{W}$ is gas constant of water vapor, $\mathrm{kJ} \mathrm{kg}^{-1} \mathrm{~K}^{-1} ; y_{\mathrm{w}}$ and $y_{\mathrm{w} 0}$ are volume fractions of water vapor at calculation and deadpoint conditions.

It is assumed that the flue-gas or air component has constant specific heat (average specific heat $C p_{\mathrm{g}}, \mathrm{kJ} \mathrm{kg}^{-1} \mathrm{~K}^{-1}$ ). Then the exergy of gas component is

$$
E_{\mathrm{g}}=C p_{\mathrm{g}}\left(T_{\mathrm{g}}-T_{0}-T_{0} \ln \frac{T_{\mathrm{g}}}{T_{0}}\right)+R_{g} T_{0} \ln \frac{\mathrm{y}_{g}}{y_{\mathrm{g} 0}}
$$

where $T_{\mathrm{g}}$ is temperature at calculation condition, $\mathrm{K} ; \bar{R}_{g}$ is gas constant of gas, $\mathrm{kJ} \mathrm{kg}^{-1} \mathrm{~K}^{-1}$; $y_{\mathrm{g}}$ and $y_{\mathrm{g} 0}$ are volume fractions of gas at calculation and deadpoint conditions.

The physic exergy carried by the dried lignite is

$$
E_{l}=C p_{l}\left(T_{d}-T_{0}-T_{0} \ln \frac{T_{d}}{T_{0}}\right)
$$

where $C p_{1}$ is the constant specific heat of lignite, $\mathrm{kJ} \mathrm{kg}^{-1} \mathrm{~K}^{-1} ; T_{\mathrm{d}}$ is the temperature of lignite at the outlet of dryer, $\mathrm{K}$.

To quantitatively compare the thermodynamic performance of various dryers, the exergy feeding rate is defined as

$$
e_{f}=\frac{E_{h}}{\lambda}
$$

where $E_{\mathrm{h}}$ is the exergy fed into the dryer by drying heat source, $\mathrm{kJ}$.

The exergy carried by the dried lignite or dryer exhaust can be recovered by heat recovered, whereas the internal exergy loss (exergy destruction) in the dryer and external exergy loss 
along with heat loss of the dryer could not be recovered. The exergy consumption rate is defined as

$$
e_{\mathrm{c}}=\frac{E_{h}-E_{l}-E_{e}}{\lambda}
$$

The exergy feeding rate $e_{\mathrm{f}}\left(\mathrm{kJ}\left(\mathrm{kg} \mathrm{H}_{2} 0\right)^{-1}\right)$ expresses the exergy feeding amount to dry $1 \mathrm{~kg}$ water out from raw lignite, and the exergy consumption rate $e_{\mathrm{c}}\left(\mathrm{kJ}\left(\mathrm{kg} \mathrm{H}_{2} \mathrm{O}\right)^{-1}\right)$ expresses the irreversibilities and heat loss of lignite dryers.

\section{Results and discussions}

We use Yimin lignite as the reference coal to carry out quantitative analysis ${ }^{[5]}$. Moisture contents of raw lignite is $39.5 \%$ and it is assumed to be dried to $15 \%$ in the dried lignite. The constant specific heat of lignite is $1.3 \mathrm{~kJ} \mathrm{~kg}^{-1}$.

\subsection{Heat balance of lignite dryers}

The heat balance of lignite dryers listed in Tables 1 and 2 is calculated. The mass flow rate of heat source for drying $1 \mathrm{~kg}$ water out from lignite is compared in Fig.2. As shown in Fig.2, the mass flow rate of heat source varies greatly. The heat released by per unit fluegas is significantly lower than that released by per unit steam. Therefore, $K_{h}$ for flue-gas dryers is bigger than that for steam dryers. The $K_{h}$ is above 29 for the moving bed dryer, because the temperature drop of flue-gas for the moving bed dryer is only $95^{\circ} \mathrm{C}$. For the steam fluid-bed dryer and rotary-tube dryer, the rates of drying medium are 1.38 and 1.49, respectively.

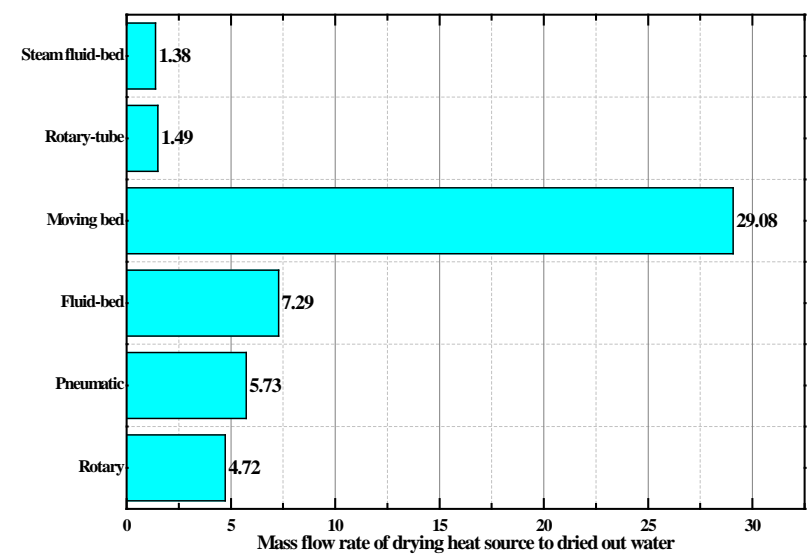

Fig. 1 Schematic diagram of Dryer. 


\subsection{Comparison of exergy feeding and consumption rates}

Based on the heat balance of lignite dryers, exergetic analyses were conducted. The exergy feeding and consumption rates for lignite dryers were compared in Fig.3. As shown in Fig.3, the exergy feeding rate and exergy consumption rate for dryers vary greatly. The flue-gas of $750{ }^{\circ} \mathrm{C}$ is used to dry lignite in the rotary dryer, so the exergy feeding rate is as big as $1837.9 \mathrm{~kJ}\left(\mathrm{~kg} \mathrm{H}_{2} \mathrm{O}\right)^{-1}$. If the exergy contained in dryer exhaust and dried lignite could be recovered, the exergy consumption rate could be decreased to $1424.8 \mathrm{~kJ}\left(\mathrm{~kg} \mathrm{H}_{2} \mathrm{O}\right)^{-1}$. The low temperature heat source is used to dry lignite for the steam dryers. The exergy feeding rates for rotary-tube dryer and steam fluid-bed dryer are 1131.7 and $955.2 \mathrm{~kJ}\left(\mathrm{~kg} \mathrm{H}_{2} \mathrm{O}\right)^{-1}$, respectively. In the steam fluid-bed dryer, no air is used as carrier gas, so more exergy could be recovered from dryer exhaust. The exergy consumption rate for steam fluid-bed dryer is only $432.6 \mathrm{~kJ}\left(\mathrm{~kg} \mathrm{H}_{2} \mathrm{O}\right)^{-1}$.

Air is always used as carrier gas for the rotary-tube dryer. In Fig.3, the mass flow rate of air for drying $1 \mathrm{~kg}$ water is assumed as $3 \mathrm{~kg}$. The mass flow rate of carrier gas for rotary-tube dryer will indeedly influence the exergy feeding rate and exergy consumption rate, which is shown in Fig.4. As shown in Fig.4, the exergy feeding rate increases linearly with mass flow rate of carrier air. For more exergy can be recovered in dryer exhaust when less air is used as the carrier gas, the exergy rate reduction of exergy consumption rate compared with exergy feeding rate decreases with the increase of mass flow rate of carrier gas.

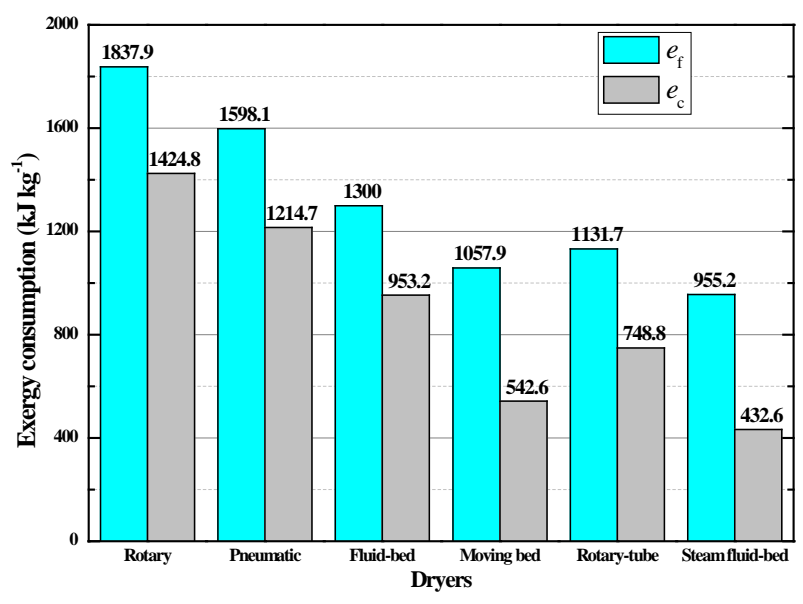

Fig. 3 Comparison of exergy consumption rate. 


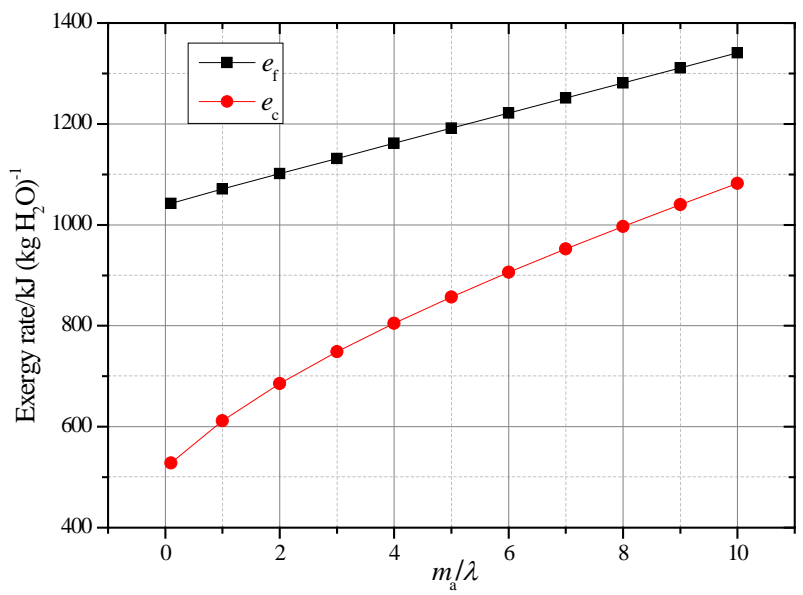

Fig. 4 Influence or carrier air on exergy feeding and consumption rates for rotary-tube dryer.

\section{Conclusions}

The heat consumption rate for lignite drying is a conventional indicator to evaluate the performance of lignite dryers. However, the drying temperature for various drying technologies are different, which means that energy at different grades is used in these drying technologies. The heat consumption rate could not evaluate the irreversibilities in drying process. Therefore, the exergetic analysis models are developed in this paper, and the exergy feeding rate and exergy consumption rate are defined as indicators for exergy analysis. Quantitative analyses on lignite dryers reveal that irreversitbilities vary greatly for lignite drying technologies. Dryers using low temperature heat as dryer heat source consume less exergy in the drying process. The exergy consumption rate for steam fluidbed dryer is the smallest, which is $432.6 \mathrm{~kJ}\left(\mathrm{~kg} \mathrm{H}_{2} \mathrm{O}\right)^{-1}$. The aim of this paper is to provide a guidance for the development and study of lignite drying technologies in the viewpoint of reduction for exergy consumption.

\section{References}

[1] Liu, M.; Li, G.; Han, X. Q.; Qin, Y. Z.; Zhai, M. X. ;Yan, J. J. Energy and exergy analyses of a lignite-fired power plant integrated with a steam dryer at rated and partial loads. DRYING TECHNOLOGY 2016, 35 (2), 203-217.

[2] Bejan, A. Advanced engineering thermodynamics. John Wiley \& Sons: 2016.

[3] Kakaras, E.; Ahladas, P. ;Syrmopoulos, S. Computer simulation studies for the integration of an external dryer into a Greek lignite-fired power plant. Fuel 2002, 81 (5), 583-593.

[4] Mujumdar, A. S.Handbook of industrial drying. CRC press: 2014.

[5] Liu, M.; Yan, J.; Chong, D.; Liu, J. ;Wang, J. Thermodynamic analysis of pre-drying methods for pre-dried lignite-fired power plant. Energy 2013, 49, 107-118. 